\title{
Knowledge management critical failure factors: A multi-case study
}

Article in VINE · February 2014

DOI: 10.1108/VINE-08-2012-0034

CITATIONS

9

2 authors:
Peyman Akhavan

Malek Ashtar University of Technology

127 PUBLICATIONS 833 CITATIONS

SEE PROFILE

Some of the authors of this publication are also working on these related projects:

Project

Technology Management, Commercialization View project 


\title{
Knowledge management critical failure factors: a multi-case study
}

\author{
Peyman Akhavan and Amir Pezeshkan \\ Department of Industrial engineering, Iran University of Science and Technology, Tehran, Iran \\ Department of Strategic Management, School of Business, Old Dominion University, USA
}

\begin{abstract}
This article is (c) Emerald Group Publishing and permission has been granted for this version to appear here (http://www.emeraldinsight.com/journals.htm?articleid=17101943). Emerald does not grant permission for this article to be further copied/distributed or hosted elsewhere without the express permission from Emerald Group Publishing Limited.
\end{abstract}

Citation: Akhavan, Peyman and Amir Pezeshkan (2014), Knowledge management critical failure factors: a multicase study, Vine: The journal of information and knowledge management systems, Vol. 44, No. 1, pp. 22-41.

\begin{abstract}
Purpose - The goal of this paper is to present the main critical failure factors extracted from analyzing 10 case studies of failure in Knowledge Management (KM) systems and projects and present a framework in which the failure factors are linked to the different stages in the cycle of KM implementation.
\end{abstract}

Design/methodology/approach - "Grounded theory" as a qualitative research technique has been applied to explore the main failure factors. Data was collected reviewing scholarly articles containing KM case studies (failure in KM implementation) and after an in-depth study applying grounded theory method - the results of main critical failure factors categorized and analyzed in specific stages of implementing KM systems.

Findings - Through review and analysis of 10 case studies, two main results were obtained: First, the main critical failure factors of KM projects were identified. Second, identified critical failure factors were traced along KM implementation cycle. A framework is proposed that shows the critical failure factors' effect in each specific stage of the KM cycle.

Practical implication - The findings are incorporated into a framework of failure factors in KM projects and the proposed framework can help practitioners in organizations to avoid factors that lead to the demise of KM systems in each stage of KM project development cycle. This multi- 
case study research and its suggested framework are also useful for academics to gain a comprehensive view of KM critical failure factors for future studies.

Research limitation - The results of this research are generalized based on cases from prior literature. However, we have tried to be as inclusive as possible to ensure a representative sample of reported KM failures. In addition, organizations do not provide accurate reports of failure in their projects because of their policies, the image of their organization, and privacy, which could affect the identification of all failure factors.

Originality/value - To our knowledge this study is the first of its kind to provide an integrated perspective of critical failure factors for the implementation of KM through the inspection of 10 case studies and maps the failure factors on $\mathrm{KM}$ implementation cycle. It provides valuable information and guidelines that will hopefully pave the way for managers to avoid failure in implementation of a KM.

Keywords - Knowledge management, Knowledge management failure, Knowledge anagement cycle, Qualitative research, Critical failure factor

Paper Type - Case study

\section{Introduction}

Knowledge management (KM) has been defined as the identification, optimization and active management of intellectual assets, either in the form of explicit knowledge held in objects or as tacit knowledge possessed by individuals or communities (Snowden 2000; Akhavan et al, 2009b). Organizations implement KM to improve efficiency and to provide effective ways of using their intellectual assets. KM is no longer an option but rather a necessity for organizations anywhere in the world (Akhavan et al, 2010) if they have to compete successfully (Singh and Kant, 2007, 2008). In a knowledge-driven economy, organizations' intangible assets are increasingly becoming a differentiating competitive factor (Jafari et al, 2007), particularly in services industries. Indeed, intangible assets such as trademarks, companies' reputation and skills pertaining to employees' know-how, and the corporate culture are recognized as the core of competitive advantage (Riege, 2005; Jafari et al, 2008). If knowledge is considered as a key resource for the organization, then it has to be exploited to create value for the firm (Desouza, 2003). For this purpose, many approaches have been suggested to manage organizational knowledge so that organizations can utilize their knowledge to improve their competitiveness in business markets (Jafari at al, 2010). Approaches to KM include the methods and instruments to deliver KM goals (Weber, 2007) and require a high level of involvement and resources. The successful implementation of KM systems is vital for organizations to be competitive in knowledge-oriented markets and industries and to avoid wasting organizational resources.

Although the history of successful experiences pertinent to the implementation of KM systems can be found in relevant documents (Jafari et al, 2009), organizations are reluctant to publish stories of failure because of their policies, the image of their organization, and privacy. 
Whereas successful KM utilizations can be outstanding sources helping to learn factors and processes which lead to success (Jafari et al, 2007), careful review of the failure stories can play an equal role in the successful implementation of $\mathrm{KM}$ initiatives. There are factors that cause KM projects to fail. These factors can demonstrate the dark side of this process for managers and reveal issues that may not be thought of or intentionally censored in the narration of successful experiences. Managers' ignorance of these factors could jeopardize the KM projects and causes the eventual wastage of organizational resources.

Attempting to underline the importance of lessons that can be learned from KM failure experiments, this paper has set out to identify and address critical failure factors (CFFs) through the analysis of 10 well-documented cases. In each case, a comprehensive examination is carried out and the complete process of KM system from initial to final implementation stages has been studied to identify the factors that were the main causes of KM failure in that case study. Finally, as one of the main contributions of this paper, the CFFs were categorized and mapped in the KM implementation cycle in an integrated view to show the susceptible factors which can endanger the successful implementation of the KM systems in each stage.

\section{Research methodology}

For this study, grounded theory (GT) - a qualitative research method - has been used due to the available rich data that could be used to facilitate the generation of theoretical results (Locke, 2001). The data used in this paper is a combination of cases from previous research and special case study for present study. The failure cases were selected through a careful and accurate search process in popular databases such as Emerald, Business Source Complete, and JSTOR. Detailed cases were selected on the basis of whether they provided required information about the complete failure process of KM in which KM projects had not been fully implemented, had been abandoned after a while, or they illustrated some important and noticeable factors that had led KM projects to failure. This search paradigm is based on an in-depth qualitative study that has some similarities to ethnography (Atkinson and Hammersley, 1994) and other forms of research that derive their theoretical outcome from naturally occurring data (Marshall and Rossman, 1989).

To analyze data in this research, data from the case studies were accumulated; an indepth case study in each case was developed. In the cases that researchers had identified some failure factors, those factors were reviewed and sometimes modified. In the next step, through categorizing and combining selected input data, main concepts were identified and their characteristics were distinguished. Distinguishing the relationships between concepts and axial and selective coding are the next stages of this step (Goulding, 2002, 2005). Open coding and subsequent selective coding were done for each case history to explore the characteristics and origin of the KM failure process in the company and to analyze the pattern of relationships among the conceptual categories. 


\section{Case studies}

\subsection{KM failure in HS}

HS (the actual name of company is disguised for confidentiality) is a Hong Kong-based company whose production plant is in China. Producing handbags and leather premium products, HS exports the majority of its products to the USA and Europe. Its head office in Hong Kong has 10 staffs: CEO, general manager, sales manager, operation manager and six other administrative staffs; its plant in China has 450 staffs, including 40 managerial, supervisory or administrative employees and 410 skilled workers.

Because of a noticeable decline in HS' business since 1998, the CEO formed a strategic group to explore the main reasons of this problem, and after two weeks they concluded that the main reason was how they managed the knowledge in their organization ans specially low level of knowledge diffusion and high level of knowledge loss. After more investigations and informal meetings with employees, the strategic group and staff accepted that employees were crucial to derive KM initiatives by utilizing their personal knowledge to learn, share, and combine with other sources of knowledge. They ran a KM project, but HS did not have a well-implemented systematic mechanism for managing knowledge inside the organization. Consequently, there was no clear feedback because the trial run of the KM initiatives was not performed in a systematic way. HS chose to pilot the KM initiative on a new product series, and it was supposed to present results in four main categories: strategic, organizational, instrumental, and output. Finally, the KM program was run officially in April 2002.

As time went by, there was no positive feedback from the program in HS and finally after 15 months of implementation, managers found that organizational performance had not been enhanced and the revenue of the firm was decreasing, so HS shut down the KM initiatives in 2003. After studying external consultants' interviews with workers and other available documents, the main factors that caused failure in KM initiatives in HS can be stated as:

- Top managers did not have suitable insight, or continuous real involvement in the program, or enough support.

- There was a lack of appropriate planning for the program.

- The reward system was not planned neither was it controlled efficiently, and there was more emphasis on monetary rewards.

- The employees did not have enough IT and other KM instrument skills.

- There was not a comprehensive and constant assessment process. 
- There were serious problems with knowledge sharing because of the emphasis on using external knowledge sources.

- Required relationships among workers were not established.

- Inappropriate culture caused individuals to be involved in the implementation of the projects mainly with short-term benefits (Adapted from Chan and Chau, 2005).

\subsection{Failure in KM initiatives of the Swedish Armed Forces (2 cases)}

In the past decade, because of rapid changes and utilization of lessons learned, the Swedish Armed Forces (SwAF), on a need basis, has attempted to implement KM in different parts of the organization several times. Some of these attempts have resulted in failure during the KM implementation. In this section, we study two cases of these KM initiatives and describe the CFFs of these cases. The most important goals of KM development in these cases have been the collection, analysis and categorization of experiences, followed by the development of technical support systems.

a) Heimdall

Heimdall was a database designed to record and categorize a large number of international missions that were completed throughout the world by SwAF. This database developed in MS Access was aimed at providing permission for SwAF personnel to undertake a mission, but after establishment of this database there were some problems that finally led to its failure

Because of security considerations, there was permission limitation for those who were doing a mission. There was no willingness among the personnel to enter required data into the database, and their fulfillment of their duties was merely an indication of the pressure from organizational obligations not based on their interest. The advantages of using the recorded data were not clarified for the personnel, and nobody knew how the data could be utilized. In addition, the interface of the database was not user-friendly. After a while, the project lost management support, and eventually these factors caused the Heimdall to be closed down (Adapted from Pettersson, 2009).

\section{b) LLDB}

As another KM attempt for using past experiences, the LLDB99 database was a collection of documented experiences in the Swedish Navy between 1996 and 1997. Another database, LLDB 2000, was developed to contain additional lesson-learned reports but this database was abandoned too. Available research and data illustrate that users had a motivation problem to place the reports in the database and to use data and search the database. In fact, users did not find a reasonable relation between data and search results. Through categorizing and summarizing the results of available research (Pettersson, 2009), the CFFs in the LLDB 2000 
case study can be stated as: problems of knowledge sharing, the vagueness of perceived image of the project, the structure of the database, and the relevance of the project task to routine tasks of the workers (Adapted from Pettersson, 2009).

\subsection{Chua and Lam (2005) multi-case study}

Chua and Lam (2005) studied five cases of KM project failure. Because their research is well documented and detailed, this research and its case studies are appropriate for our study, so their five case studies are summarized in this section, and their CFFs are investigated.

a) KM failure in a global bank

A global bank with several branches in 70 countries decided to implement some KM solutions in the form of intranet projects (Officeweb, GTSnet, and Iweb) to integrate its services into a knowledge network. The purpose of the Officeweb was to create a community of branch managers to share local knowledge. The GTSnet was aimed to integrate dissimilar information throughout the different branches and provide integrated information for users in the Transaction Service Division. The Iweb was supposed to have two main roles: a central information repository and a platform for users to share experiences especially about intranet.

Although the Iweb project was more successful than others, all of these projects failed. The reasons of the failure in these projects Chua and Lam (2005) mentioned can be described as:

- Inappropriate infrastructure (bandwidth) for trial version of Officeweb.

- The CFFs of GTSnet were lack of involvement of targeted end users, lack of efforts to convince the users about its impacts on division success, using external IT consultants that had no relevant business knowledge.

- The main problem of the Iweb was its inability to motivate workers to share their knowledge.

b) KM failure in a pharmaceutical company

This case is an American-owned global pharmaceutical company that devoted a notable amount of financial resources to implement three KM projects: "lesson learned”, "warehouse”, and "electronic café".

"Lesson learned" was aimed at documenting the experiences of work groups at the end of a major drug development process. The goals were to record the corporate lessons learnt and to prevent the loss of knowledge in the drug development process.

"Warehouse" was a groupware. Its content was based on "lesson learned" debriefings. Besides attaining solutions to solve problems, its target was to conduct data-mining on the details of administrative and decision-making processes. 
"Café" was a free virtual space for individuals to digress from reality and discuss subjective and hypothetical issues and to share personal experiences among the organization's innovators. It was a set of websites devoted to the drug development programs.

After implementation, none of these projects reflected successful results or the outcomes for which they were planned. Below are some reasons of the failure of these projects:

- The scope of the "lessons" was limited to the existing procedures. There was no investigation process for lessons; moreover, the "lessons" led to a list of dissatisfactions with how standard operating procedures were applied while it was aimed at critical feedbacks on the procedures. Regarding these facts, "lessons" became a reinforcement of routines.

- "Warehouse" was not adapted to the context of workgroups so, it was considered irrelevant to day-to-day operational processes. In addition, using the "warehouse" was considered by the workers as a lack of expertise; therefore, "warehouse" could not attract contributions from the individuals.

- Because access to the "café" was exclusive its expansion was limited. Also, free nature of the "café" that allowed the users to discuss completely hypothetical issues made it impractical and irrelevant (adapted from Chua and Lam, 2005).

c) KM failure in a manufacturing company

A European manufacturing company producing products in 30 countries, decided to implement three KM projects named "production project", "supply-chain project” and "design project". The targets of the "production project" were to record and to share the knowledge of production methods in order to cut production costs. The aim of implementing the "supply-chain project" was to distribute and to share products' knowledge in the supply chain to improve the understanding of the effects of product design on the economics of transport and warehousing and to enhance product functionality. The "design project" was implemented to improve product design so that designers could construct prototypes with minimal raw materials.

After implementation, "production" was able to extract and transfer knowledge to the plants that needed it, but its aim of promoting the application of new knowledge resulted in a mixed level of success. "Supply" was a codification of knowledge culled from customers, warehouse delivery centers, transporters, and end-consumers; however, it was under-utilized. "Design" was a highly sophisticated software system but it was largely neglected by designers and became obsolete after a while (Chua and Lam, 2005).

The reasons for KM failure in the manufacturing company were (Chua and Lam, 2005):

- In the "production project”, from 40 plants, 10 plants did not use new knowledge because they did not realize there was a gap in production performance in their 
plants. They did not fully grasp the advantages of applying new knowledge. It was discovered later that the plants that put the new knowledge into practice had improved their production performance considerably.

- The result of the "design project" was too complicated to be understood. It did not accomplish the result that were hoped for which was reducing raw material and the number of prototypes. Owing to the lack of usage, “design” was not updated and failed.

The "supply-chain project" did not provide required information for users. It could not reach its primary targets to increase sales volume for sales staffs and to create better products for designers (Chua and Lam, 2005).

d) KM failure in a European-headquartered company

Senior managers of a European-headquartered company decided to assemble a KM team to implement a KM initiative. The aim was cost-effectiveness, competitiveness, and a better management of business risks. The initiative contained a set of plans such as creating informative web pages for the management and all business units, organizing staffs into communities of practice and identifying internal knowledge champions. IT and media affairs , two departments responsible for developing the website and intranet in the KM initiative, held conflicting views about the IT systems. The members of the KM team suspected that IT managers were following a dominant position in the company; hence conflicts in the KM team multiplied. Finally, because of these issues as well as external market conditions, the KM team disbanded. The main visible factors leading to the failure in this case are (Chua and Lam, 2005):

- Top managers did not commit strongly enough to the projects, and the KM initiative did not have strategic importance in the organizations.

- The conflicts between the departments of IT and media affairs were not managed by the KM team, and these conflicts reverberated throughout the team.

- $\quad$ The KM team failed to execute a pilot version of the projects to identify the barriers.

e) KM failure in a global company

"A global company, one of the top ten organizations in its industry, lost a number of deals on account of its inability to offer integrated solutions in the order handling line of business. In response, the management commissioned a KM project known as Alpha whose objective was to create a blueprint for gaining and maintaining the leadership of global order handling services market. Underpinning Alpha was a comprehensive attempt to manage the knowledge across the company." 
Within Alpha project, several functions and teams such as business architecture, IT, knowledge content, and design were formed. One of Alpha's priorities was to build a network of "knowledge-enabled worktables" to provide staff with customized access to Alpha's knowledge base. The IT team could not complete the first worktable for the sales function on schedule because of the problems which exist in the initial stage of using a new technology and also, the poor translation of design requirements to system functionalities. However, during this period, the knowledge content and design team had already developed a large amount of content. Being worried that a delay could reduce interest in KM, the team asked a external vendor to develop an intranet system as a quick alternative to make its content available. The IT team perceived the introduction of an outside vendor as an invasion into its territory and also, other staffs were skeptical about the intranet. By the end of the year, the viability of the worktable was in doubt. Alpha was perceived to be losing control over its IT-related projects because of the high dependence and unsustainable expenditure on external IT resources. Management closed Alpha because it lost faith in knowledge management (Chua and Lam, 2005).

The main failure factors and reasons are:

- Critical business knowledge that could interface many functional groups was neglected because of the KM style.

- Because the main focus and reliance was on IT, other important factors such as human and behavioral issues and tacit knowledge were not sufficiently considered.

- By using different external consultants, the company could not apply and use a clear advisory solution.

- The increasing cost of sustaining the initiative caused managers to leave the KM project (adapted from Chua and Lam, 2005).

\subsection{KM failure in a telecommunication company}

The company mentioned in this case study is among the largest providers in the telecommunication industry. It has around 6000 employees in more than 150 countries. The company has a KM function in the human resources department. Some various KM initiatives were implemented in the company to support business strategy. These initiatives can be categorized in four areas. First, initiatives implemented to improve productivity and efficiency of the employees. Second, initiatives implemented to create a KM-oriented culture. Third, initiatives implemented to help the company to become a solution-oriented firm that sells solutions instead of products. Fourth, initiatives implemented to improve innovativeness of the company (Adapted from Pukkila, 2009).

None of these KM initiatives was welcomed by the employees. After studying the case, some factors can be addressed as CFFs: 
- $\quad$ Top managers' consistent support for KM was missing.

- There was no shared understanding because of poor communication and coordination.

- Relationships of KM with real business issues were not clarified.

- There was a lack of united KM culture.

- Current IT infrastructure was not appropriate for KM initiative requirements.

- Issues such as cuuting the costs and expenditures damaged the KM initiatives.

- Sufficient resources were not allocated to KM initiatives (Pukkila, 2009).

\subsection{KM failure in an Iranian transportation company}

In this study, we investigate the procedure of a comprehensive KM system implementation in an Iranian company in the transportation industry. VRT Company (the actual name of company is disguised for confidentiality) decided to implement an overall KM system to redefine its structure towards a knowledge-based structure. Organizational goals of KM implementation were to prepare a suitable context for sharing personal and organizational experiences, to generate a knowledge sharing culture within the organization, to identify the knowledge strengths and weaknesses of the company in the transportation area, and to prevent knowledge loss when employees leave the organization.

In the first phase of the KM project, a web-based software was implemented. The aim of this software was to assess overall KM implementation. In this step, required instructions were prepared and some training programs were initiated. Managers assumed that after the first phase and developing the physical systems KM system would be implemented completely and would be ready to be used by the employees but this project was stopped in the first phase.

After some interviews and doing a field study in the company, CFFs were extracted and were presented to the organization's experts participating in the KM projects. Failure factors were later modified based on their feedback. Following items are final CFFs after being approved by the firm's experts:

- Using the knowledge of coworkers was considered as a weakness of individuals.

- Lack of using right individuals with relevant knowledge and experiences in KM team and also as external consultants.

- Lack of motivation among the employees which was not considered by the KM team.

- Overreliance on KM technological tools and ignoring the behavioral factors. 
- High amount of the project's costs.

- Lack of top managers' commitment during the project

- Lack of compatibility between what employees were doing and new system developed in the project.

- Inability of workers to apply KM tools (lack of appropriate knowledge and weak training system)

- Failure in motivating the share of the employees knowledge

- Lack of explicit strategy and detailed plan for KM project.

\section{The CFFs in KM case studies}

After detailed examination of the cases and analyzing the results through grounded theory methodology, the main CFFs were extracted from the case studies. Table 1 illustrates the result. The main CFFs are mentioned in the table for each case. 


\begin{tabular}{|c|c|c|c|c|c|c|c|c|c|c|c|}
\hline & Critical Failure Factors & W & 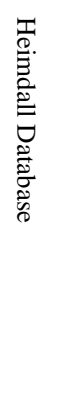 & $\underbrace{E}_{\sigma}$ & 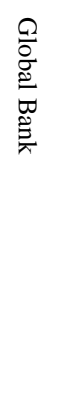 & 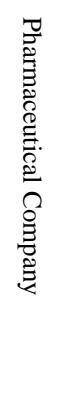 & 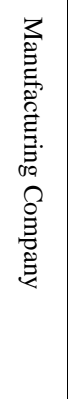 & 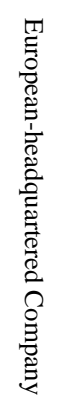 & 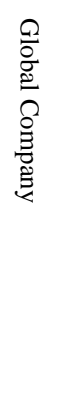 & 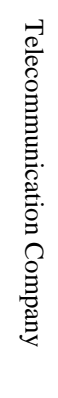 & 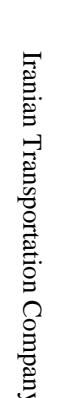 \\
\hline 1 & Lack of top managers familiarity with aspects of KM projects & $\checkmark$ & & & & & & & & & \\
\hline 3 & Inappropriate members of KM team & & & & & & & & & & $\checkmark$ \\
\hline 4 & Lack of detailed planning and timing for KM project & $\checkmark$ & & & & & & & & & \\
\hline 5 & Lack of separate and sufficient budget for KM & & & & & & & & $\checkmark$ & $\checkmark$ & \\
\hline 6 & Lack of KM-oriented culture in organization & $\checkmark$ & & & & & & & & $\checkmark$ & $\checkmark$ \\
\hline 7 & Lack of commitment and support of top management for KM & $\checkmark$ & & $\checkmark$ & & & & $\checkmark$ & & $\checkmark$ & $\checkmark$ \\
\hline 8 & Nonconformities between current systems and new systems & & & & & & & & & & \\
\hline 9 & Improper technical infrastructure & & $\checkmark$ & & $\checkmark$ & & & & & $\checkmark$ & \\
\hline 10 & Resistance against the change in organization & & $\checkmark$ & & & & & & & & $\checkmark$ \\
\hline 11 & Inability of KM team for distinguishing organizational relations & & & & $\checkmark$ & & & & & & $\checkmark$ \\
\hline 12 & Overreliance on technology & & & & & & & & $\checkmark$ & & \\
\hline 13 & Project cost & & $\checkmark$ & & & & & & $\checkmark$ & & \\
\hline 14 & Lack of knowledge sharing because of knowledge speculation & & & $\checkmark$ & $\checkmark$ & $\checkmark$ & & & & & $\checkmark$ \\
\hline 15 & Wrong perceived image of KM & & & $\checkmark$ & $\checkmark$ & $\checkmark$ & & & & & \\
\hline 16 & Inappropriate knowledge structure & & $\checkmark$ & $\checkmark$ & & & & & $\checkmark$ & & $\checkmark$ \\
\hline 17 & Irrelevant knowledge with inappropriate flow and stream & & & & $\checkmark$ & $\checkmark$ & $\checkmark$ & & & & \\
\hline 18 & Lack of sufficient involvement of workers & & $\checkmark$ & $\checkmark$ & $\checkmark$ & & $\checkmark$ & & & & \\
\hline 19 & Lack of conflict management & & & & & & & $\checkmark$ & $\checkmark$ & & \\
\hline 20 & Lack of efficient strategy for development and rollout & & & & & $\checkmark$ & & $\checkmark$ & & & $\checkmark$ \\
\hline 21 & Inefficient reward system & & & & & $\checkmark$ & & & & & $\checkmark$ \\
\hline 22 & Unfamiliarity of workers with KM tools & $\checkmark$ & & & & & & & & & $\checkmark$ \\
\hline 23 & Not measuring and evaluating the KM project result & $\checkmark$ & & & & & $\checkmark$ & $\checkmark$ & & & $\checkmark$ \\
\hline 24 & Lack of required relation among workers & $\checkmark$ & $\checkmark$ & $\checkmark$ & & & & & & $\checkmark$ & \\
\hline 25 & Not clarifying the KM result relation to routine tasks & & & & & & $\checkmark$ & & & $\checkmark$ & \\
\hline 26 & Weak usability of KM system & & & & & & $\checkmark$ & & & & \\
\hline 27 & $\begin{array}{l}\text { External consultants' weakness in business knowledge and } \\
\text { organizational relation }\end{array}$ & & & & $\checkmark$ & & & & $\checkmark$ & & $\checkmark$ \\
\hline
\end{tabular}

Table 1: Main critical failure factors 


\section{The framework of CFFs in KM projects}

For a better understanding of factors leading to failure in $\mathrm{KM}$ efforts, this research is going to trace each individual factor in the KM process to clarify its role in KM failure. For this purpose, one of the KM cycle models showing the KM process clearly has been selected through a Delphi panel with academic experts in knowledge management field. The main selection criterion of the model was comprehensiveness of the model and its strength in providing detailed stages of KM systems implementation. After identifying the appropriate model and as a result different stages of KM implementation, extracted CFFs mapped on the proper stage where they had happened based on the content analysis conducted on each case. Result is a framework which will be discussed later in the paper.

Akhavan et al. (2009) suggested a framework for the KM cycle and identified seven stages for this cycle. This framework has been demonstrated in Figure 1.

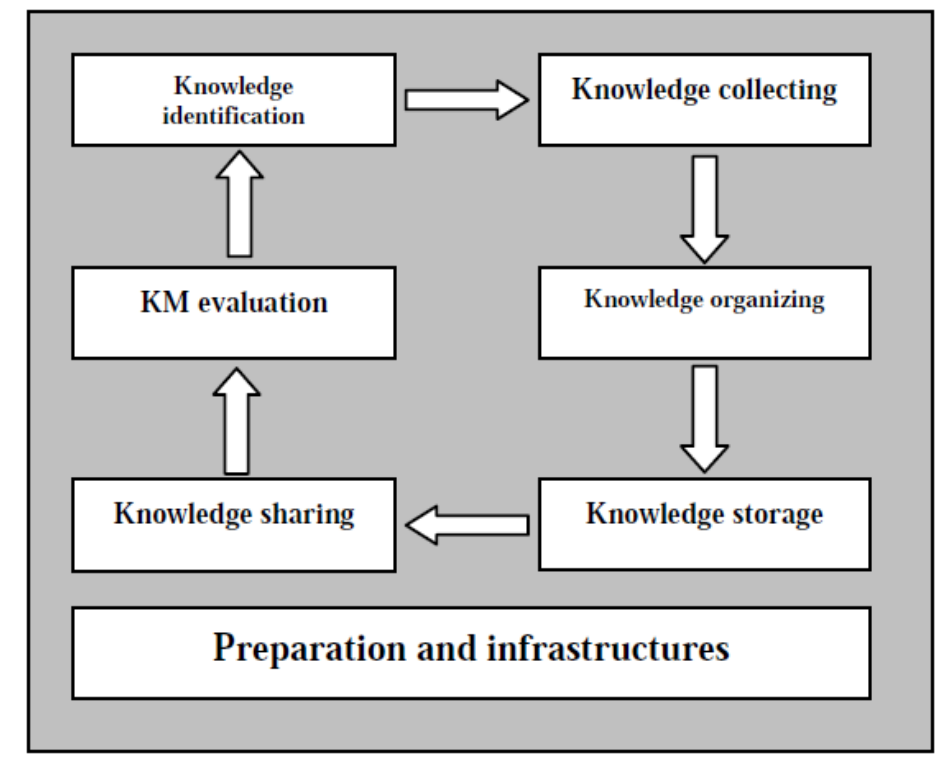

Figure 1: KM cycle (Akhavan et al., 2009)

Based on the stages of the cycle illustrated in Figure 1, the process of KM implementation in each case was examined to trace CFFs in the stages of the KM cycle in which they occurred. The resulted framework is depicted in Table 2. 
Table 2: Suggested framework of KM CFFs based on KM cycle

\begin{tabular}{|c|c|c|c|c|c|c|c|}
\hline & $\begin{array}{c}\text { Infrastructure } \\
\text { and } \\
\text { preparation }\end{array}$ & Identification & Collecting & Organizing & Storage & Sharing & Evaluation \\
\hline Lack of familiarity with aspects of KM projects of top managers & $\checkmark$ & & & & & & \\
\hline Inappropriate members of KM team & $\checkmark$ & & & & & & \\
\hline Lack of detailed planning and timing for $\mathrm{KM}$ project & $\checkmark$ & & & & & & \\
\hline Lack of separate and sufficient budget for KM & $\checkmark$ & & & & & & \\
\hline Lack of KM-oriented culture in organization & & & & & & $\checkmark$ & \\
\hline Lack of commitment and support of top management for KM & $\checkmark$ & & & & & & $\checkmark$ \\
\hline Nonconformities between current systems and new systems & & & $\checkmark$ & $\checkmark$ & $\checkmark$ & & \\
\hline Improper technical infrastructure & $\checkmark$ & & & & & & \\
\hline Resistance against the change in organization & & & & & & $\checkmark$ & \\
\hline Inability of KM team for distinguishing organizational relations & & & & $\checkmark$ & & & \\
\hline Overreliance on technology & & & & & & $\checkmark$ & \\
\hline Project cost & $\checkmark$ & & & & & & \\
\hline Lack of knowledge sharing because of knowledge speculation & & & & & & $\checkmark$ & \\
\hline Wrong perceived image of KM & & & & & & $\checkmark$ & \\
\hline Inappropriate knowledge structure & & & $\checkmark$ & $\checkmark$ & $\checkmark$ & & \\
\hline Irrelevant knowledge with inappropriate flow and stream & & & & $\checkmark$ & & & \\
\hline Lack of sufficient involvement of workers & & $\checkmark$ & & & & $\checkmark$ & \\
\hline Lack of conflict management & & & & & & $\checkmark$ & \\
\hline Lack of efficient strategy for development and rollout & & & & & & & $\checkmark$ \\
\hline Inefficient reward system & & & & & & $\checkmark$ & \\
\hline Unfamiliarity of workers with KM tools & & & & & & $\checkmark$ & \\
\hline Not measuring and evaluating the KM project result & & & & & & & $\checkmark$ \\
\hline Lack of required relation among workers & & & & & & $\checkmark$ & \\
\hline Not clarifying the KM result relation to routine tasks & & & & & & $\checkmark$ & \\
\hline Weak usability of KM system & & & $\checkmark$ & $\checkmark$ & $\checkmark$ & & \\
\hline $\begin{array}{l}\text { External consultants' weakness in business knowledge and } \\
\text { organizational relation }\end{array}$ & & $\checkmark$ & & $\checkmark$ & & & \\
\hline
\end{tabular}

Preparation and infrastructures is a fundamental stage in $\mathrm{KM}$ cycle in which the foundation of the KM process is built. The main decisions about the conditions and quality of the $\mathrm{KM}$ system are made in this step. Developing required infrastructures such as those related to information technology can facilitate the implementation of knowledge management initiatives (Shaabani et al., 2012; Zaied, 2012; Choi et al., 2010). In failure cases, factors such as separated budget, wrong estimated costs, and improper infrastructure emerged in this stage. Because the $\mathrm{KM}$ team is formed in the initial stage, the failure factors related to it such as inappropriate KM team member and leader appeared in this stage. If the top managers of the organization are not convinced to support the KM project, the detrimental effects of that can come out in the beginning stage in the form of such factors as lack of familiarity with aspects of KM projects and lack of commitment and support of top management for KM. Study of the cases proved these premises.

The next step is identification. In this step, the required knowledge that can be helpful for an organization based on its business domains and knowledge strategies are identified so that they can be collected later. Since identifying critical knowledge is a challenging task which will affect the firm as a whole (Love et al., 2012), lack of sufficient involvement of workers in this step may lead to weakness in identification of relevant and useful knowledge and can impose (c) Emerald Group Publishing 
serious dangers on the KM process. Also, weakness of external consultants in business knowledge can in turn result in their failure to identify vital and important knowledge for organization in this phase.

In the collection stage, the identified knowledge is gathered to be used. In addition, technology which can act as "enabler" of the knowledge acquisition (Milles and Smith, 2011) is used in this phase to design and prepaer knowledge bases, documentation systems and so forth based on the nature of required knowledge. Thus, the main threats in this stage were nonconformities between current systems and new systems, inappropriate knowledge structure which is formed initially in this step, weak usability of KM system whose architecture is prepared in collection step.

Organization is the step in which collected knowledge is structured and specialized to be utilized within the organization. Akhavan et al. mentioned some indicators for this step: IT based KM architecture, knowledge engineering tools, equipped knowledge bases, data mining, content analysis, and text mining technologies. As can be perceived from these indicators, this step is more technical than others, thus it can be more vulnerable in technical areas. If the system developed in this stage does not conform to the current system, then the resulting conflict can be so confusing that users will eventually abandon new system which will doom the KM system. Weakness of KM team is another factor which can affect KM initiative in this stage. Having low information about organizational relations, KM team members and external consultants may design and develop a KM system that cannot be implemented and executed in the current organizational structure. Not having applicable structure and desirable flow among the actors inside the firm, the knowledge organized in this step may transform into one of CFFs. As another technical step, storage has the same situation and its potential failure factors can be seen in Table 2.

Sharing has the greatest number of failure factors. As can be interpreted from Table 2, behavioral and managerial issues such as KM-oriented culture, resistance against change, lack of conflict management, and reward system, most of which are related to the workers are potentially CFFs. So not paying enough attention to the employees, their needs, and the factors that affect them in relation to the KM process can jeopardize KM systems because they should work to the system and the main and primary goal of any $\mathrm{KM}$ system is encouraging the knowledge workers of a firm to share their knowledge and use other co-workers' knowledge and experiences to accomplish the organizational goal more efficiently (Bhatti et al., 2011).

If the KM system, like most of other systems, is not evaluated, and its shortcomings are not eliminated after implementation, the system will become outdated and users will gradually ignore it. Having no plan for evaluating the result in this stage stems from the lack of top managers' commitment to the KM. Lack of efficient strategy for development and rollout and neglecting the evaluation of the KM project result are failure factors in this stage of KM cycle. 
After recognizing the main CFFs in each stage of the KM cycle, we asked some expert scholars in the KM context to rank CFFs based on their importance in each stage according to their actual effects in each case. Due to resource limitation, having prioritized CFFs can help organizations to focus on the most important factors which may endanger the KM strongly. Table 3 show the CFFs with their relative ranks based on their importance in each stage. The final result is based on an iterative process following the Delphi panel rationale.

Table 3: prioritized CFFs in each stage of KM cycle

\begin{tabular}{|c|c|c|c|c|c|c|c|}
\hline & $\begin{array}{c}\text { Infrastructure } \\
\text { and } \\
\text { preparation }\end{array}$ & Identification & Collecting & Organizing & Storage & Sharing & Evaluation \\
\hline \multirow{2}{*}{$\begin{array}{l}\text { Lack of familiarity with aspects of KM projects of top managers } \\
\text { Inappropriate members of KM team }\end{array}$} & 4 & & & & & & \\
\hline & 2 & & & & & & \\
\hline Lack of detailed planning and timing for KM project & 3 & & & & & & \\
\hline Lack of separate and sufficient budget for KM & 7 & & & & & & \\
\hline Lack of KM-oriented culture in organization & & & & & & 1 & \\
\hline \multirow{2}{*}{$\begin{array}{l}\text { Lack of commitment and support of top management for KM } \\
\text { Nonconformities between current systems and new systems }\end{array}$} & 1 & & & & & & 1 \\
\hline & & & 2 & 4 & 2 & & \\
\hline Improper technical infrastructure & 5 & & & & & & \\
\hline Resistance against the change in organization & & & & & & 11 & \\
\hline \multirow{2}{*}{$\begin{array}{l}\text { Inability of KM team for distinguishing organizational relations } \\
\text { Overreliance on technology }\end{array}$} & & & & 1 & & & \\
\hline & & & & & & 10 & \\
\hline Project cost & 6 & & & & & & \\
\hline Lack of knowledge sharing because of knowledge speculation & & & & & & 2 & \\
\hline Wrong perceived image of KM & & & & & & 7 & \\
\hline Inappropriate knowledge structure & & & 3 & 6 & 3 & & \\
\hline Irrelevant knowledge with inappropriate flow and stream & & & & 5 & & & \\
\hline Lack of sufficient involvement of workers & & 1 & & & & 3 & \\
\hline Lack of conflict management & & & & & & 9 & \\
\hline Lack of efficient strategy for development and rollout & & & & & & & 2 \\
\hline Inefficient reward system & & & & & & 8 & \\
\hline Unfamiliarity of workers with KM tools & & & & & & 5 & \\
\hline \multirow{2}{*}{$\begin{array}{l}\text { Not measuring and evaluating the KM project result } \\
\text { Lack of required relation among workers }\end{array}$} & & & & & & & 3 \\
\hline & & & & & & 4 & \\
\hline \multirow{2}{*}{$\begin{array}{l}\text { Not clarifying the KM result relation to routine tasks } \\
\text { Weak usability of KM system }\end{array}$} & & & & & & 6 & \\
\hline & & & 1 & 3 & 1 & & \\
\hline $\begin{array}{l}\text { External consultants' weakness in business knowledge and } \\
\text { organizational relation }\end{array}$ & & 2 & & 2 & & & \\
\hline
\end{tabular}




\section{Does the type of the firms matter?}

Based on the CFFs explored in this paper and the different stages of the KM implementation and according to what was observed during the executing KM initiatives in each case, we believe that we can classify organizations in terms of the stages of the KM cycle in which there is greater possibility for them to face failure. Our perspective for such classification is Resource Based View (RBV). RBV view firms as a bundle of resources and capabilities which are one of the most determinants of firm's success (Barney, 1991; 2001). In recent years, aligned with the global movement towards knowledge-orientations businesses, we have seen a slight shift in RBV to knowledge based view (KBV) perspective. Scholars in KBV perspective argue that knowledge is the intangible resources which enable firms to utilize and combine other tangible resources in a way that differentiate them from other competitors (Hammami and Triki, 2011). Knowledge management initiatives are executed to enable firms to enhanced organizational learning and as a result help to apply organizational knowledge and know-how to enhance the resource application (Godé and Barbaroux, 2012).

Based on what we reviewed in mentioned cases, we believed that there is a mutual dependency between KM and organizational resources. While KM initiatives deliver several benefits in order to utilizing firm's resources in more efficient ways, KM initiatives depend on some organizational resources to be designed and implement successfully. Based on the availability of resource endowments and organizational structures as two important factors in KM implementation (as mentioned), we divide organizations into two categories: Small Entrepreneurial Firms and Big Incumbent Firms. Entrepreneurial firms are usually small firms in early stage of the business life cycle formed by an individual or a group of entrepreneurs with limited resources (Covin, 1991). As we mentioned before, early stages of execution of KM initiatives are more technical and resource consuming. Internalizing (buying) one of the KM best practices in the market or designing and implementing a customized new system exclusive to the firm and its needs would require noticeable amount of the financial and non-financial resources. The story is the same when firms have to create appropriate infrastructures and collect the required knowledge from outside the boundary of the firm. Having limited resources, we believe entrepreneurial firms are more vulnerable in early stages of the KM implementation cycle where they need to devote resources to it while they may not have sufficient resources. While in early stages of KM they may confront different risks, entrepreneurial firms, because of their organizational culture and small size which enhance the team working in such firms (Knockaert et al., 2011), are expected to have successful knowledge sharing practices and also because of the team work culture and smaller number of knowledge workers the evaluation of the KM initiatives will be easier and more effective in these firms.

On the other side, incumbent firms will be expected to have large number of employees and big repertoire of different resources. As we discussed, KM initiatives demand devoted resources in early stages. Incumbent firms are resourceful and have distinctive slack resources (Rosenbusch et al., 2011) which enhance their chance of providing sufficient infrastructure and 
technological assets and requirements. Therefore, we expect that these firms would not have the problems smaller firms face in early stages. But as we observed in the cases, the main problems start from the knowledge sharing stage for big firms. The large number of employees and having complex multidivisional structure make the knowledge sharing more complicated and increase the hazard of the opportunistic behaviors among the workers which hinder them from knowledge sharing to maintain their monopoly over what they know (Kapoor and Ander, 2012). Therefore, based on what we explore in the cases mentioned in this paper, we can conclude that big incumbent firms are more vulnerable in factors related to knowledge sharing and contribution of employees.

\section{Conclusion}

Nowadays with the global movement of firms in many industries towards knowledge based firms, the KM systems and projects as the means of maintaining and developing the organizational knowledge have gained significant importance from the perspective of both practitioners and researchers. Understanding and knowing the potential failure factors can help organizations to steer clear of the failure of KM attempts which can impose noticeable wastage of organizational resources.

This paper uses a grounded theory method to come up with its results. In this process which can be called a qualitative meta-analysis of the previous studies, 10 different cases from prior literature and a new case were thoroughly studied. These cases explain the process of the failure of KM implementation projects and initiatives. In the first phase resulted from the grounded theory approach used to scrutinize the cases, the most important CFFs were identified. Identification of the most important CFFs of the KM initiatives based on a population drawn from literature and our new case is the first contribution of the paper. In fact, the results of this paper drawn from several samples (which all together can be called a population) through a grounded theory approach are more reliable to rely on by future studies and also for mangers.

In the second phase of the study, after conducting a deep study in each case, the stage(s) in which failure factors emerged was determined. The result was a framework mapping different CFFs on the appropriate stage of the KM cycle. The draft framework articulated based on the findings was validated through a Delphi panel which resulted in the final framework (shown in Table 2). The framework shows the susceptible failure factors in six different stages of KM implementation cycle based on the results of the present study.

According to the suggested framework of the paper, a considerable number of the potential failure factors can emerge in the preparation phase. Arranging KM team with members who do not have appropriate knowledge about KM systems or sufficient knowledge about the organization can lead to the demise of the KM projects in the initial stage. 
Most CFFs occur in the sharing stage of KM implementation. In many cases, there was more emphasis on technological issues than human and behavioral issues. In the sharing phase, workers should be motivated to become involved in sharing the knowledge and indeed, KM systems are developed for this purpose so success in this stage is essential and vital for KM projects. There are many factors that can halt the project in this stage of the KM cycle. As seen in the framework (Table 2), most of the CFFs are behavioral issues such as lack of KM-oriented culture, worker resistance, and conflict management which are all about the employees, the main target of KM initiatives. To eliminate these failure factors, managers should prepare a suitable plan such as a prudent change management plan prior to implementation. They should pay utmost attention to the workers and issues related to them.

Similar to any other research, this study has some imitation noteworthy to mention. The results of the research and the framework are based on the cases found in available literature and a new case study conducted to enrich the sample and capture possible missed CFFs. However the authors have attempted to consider any cases available with detailed required information which allowed drawing a reasonable insight about the KM failure process and factors, but there might be other factors which have not explored in cases studied in this paper. Organizations are not willing to disclose the complete story of the failure in their projects and attempts because of political and competitive issues, and also their concern about the image of their organization. However, we have tried to be as inclusive as possible to ensure a representative sample of reported KM failures.

In terms of the practical and theoretical implementation, this framework helps managers and practitioners to recognize the potential failure factors in each stage of the $\mathrm{KM}$ cycle and avoid them. It is reasonable to argue that for managers in large companies with complex structure and large number of employees who will be involved in the KM, the main concern should be creating such incentives that convince knowledge workers to share their knowledge and utilize others' knowledge and experiences. Managers in small entrepreneur businesses, due to resource limitation, should be more accurate in assessing what they need and expect from the KM systems and create appropriate infrastructure via using their available resources efficiently. For researchers, the framework and CFFs that were identified based on the examined cases can be a reliable reference for future research. They can focus on each failure factor and propose practical solutions to avoid it. Determining the isolated effect of each failure factor, using the success factor as an antidote against each failure factor one-on-one to neutralize them, and explaining the probable relationships among failure factors can be areas of potential future study in which the results of this study could prove helpful. 


\section{References}

- Akhavan, P., Hosnavi, R. and Sanjaghi, M. (2009), “Towards knowledge management: an exploratory study for developing a KM framework in Iran”, International Journal of Industrial Engineering \& Production Research, Vol. 20 No. 3, pp. 113-120.

- Akhavan, P., Jafari, M. and Fathian, M. (2005), "Exploring failure-factors of implementing knowledge management systems in organizations”, Journal of Knowledge Management Practice, Vol. 11 No. 2.

- Akhavan, Peyman, Hosnavi, R., and Sanjaghi, M. (2009b), Identification of knowledge management critical success factors in Iranian academic research centers, Education, Business and Society: Contemporary Middle Eastern Issues, Vol. 2, No. 4, pp. 276-288.

- Akhavan, Peyman, Adalati, Mohammad, Sharifi, Sara, and Reza Hosnavi (2010), The challenges of knowledge management portals application and implementation: An Iranian organizations case study, International Journal of Industrial Engineering Computations, Vol. 1, No. 1, pp. 79-93.

- Atkinson, P. and Hammersley, M. (1994), Handbook of Qualitative Research, Sage, Thousand Oaks, CA.

- Barney, J. B. (1991), "Firm resources and sustained competitive advantage”, Journal of Management, Vol. 17, pp. 99-120.

- Barney, J. B. (2001), "Is the resource-based "view" a useful perspective for strategic management research? Yes”, Academy of Management Review, Vol. 26, pp. 41-56.

- $\quad$ Bhatti, W. A., Zaheer, A., Rehman, K. U. (2011), "The effect of knowledge management practices on organizational performance: A conceptual study”, African Journal of Business Management, Vol. 5 No. 7, pp. 2847-2853.

- Cécile Godé, Pierre Barbaroux, (2012),"Towards an architecture of organizational learning: Insights from French military aircrews", VINE: The journal of information and knowledge management systems, Vol. 42 No. 3. In press.

- Chan, I. and Chau, P.Y.K. (2005), "Getting knowledge management right: Lessons from Failure”, International Journal of Knowledge Management, Vol. 1 No. 3, pp. 40-54.

- Choi, S. Y., Lee, H., Yoo, Y. (2010), “The impact of information technology and transactive memory systems on knowledge sharing, application, and team performance: a field study”, MIS Quarterly, Vol. 34 No. 4, pp. 855-870.

- Chua, A. and Lam, W. (2005), “Why KM projects fail: a multi-case analysis”, Journal of Knowledge Management, Vol. 9 No. 3, pp. 6-17. 
- Covin, J. G., Slevin, D. P. (1991), "Entrepreneurial versus conservative firms: A comparison of strategies and performance”, Journal of Management Studies, Vol. 28, pp. 439-462.

- Desouza, K.C. (2003), "Knowledge management barriers: Why the technology imperative seldom works”, Business Horizons, Vol. 46 No. 1, pp. 25-29.

- Goulding, C. (2002), Grounded Theory: A Practical Guide for Management, Business and Market, Researchers, Sage, London.

- Goulding, C. (2005), “Grounded Theory, Ethnography and Phenomenology: A Comparative Analysis of Three Qualitative Strategies for Marketing Research”, European Journal of Marketing, Vol. 39 No. 3/4, pp.294-308.

- Hammami, S. M., Triki, A. (2011), "Exploring the information technology contribution to service recovery performance through knowledge based resources”, VINE: The journal of information and knowledge management systems, Vol. 41 No. 3, pp. 296-314.

- Jafari,Mostafa, Rezaeenour, Jalal, Akhavan, Peyman and Mehdi N. Fesharaki (2010), Strategic knowledge management in aerospace industries: a case study, Aircraft Engineering and Aerospace Technology: An International Journal, Vol.82, No. 1, pp.60-74.

- Jafari, Mostafa, Fathian, Mohammad, Jahani, Alireza and Peyman Akhavan (2008), Exploring the contextual dimensions of organization from knowledge management perspective, Vine: The journal of information and knowledge management systems, Vol. 38, No. 1, pp. 53 - 71.

- Jafari, Mostafa and Peyman Akhavan (2007), Essential Changes for Knowledge Management Establishment in a Country: a Macro Perspective, European Business Review Journal, Vol. 19, No. 1, pp. 89-110.

- Jafari, Mostafa, Akhavan, Peyman and Ashraf Mortezaei (2009), A review on knowledge management discipline, Journal of Knowledge Management Practice, Vol. 10, No. 1, pp.1-23.

- Jafari, Mostafa, Fathian, Mohammad, Jahani, Alireza and Peyman Akhavan (2008), Exploring the contextual dimensions of organization from knowledge management perspective, Vine: The journal of information and knowledge management systems, Vol. 38, No. 1, pp. $53-71$. 
- Jafari, Mostafa, Akhavan, Peyman, Fesharaki, Mehdi, and Mohammad Fathian (2007), Iran aerospace industries' KM approach based on a comparative study: a benchmarking on successful practices, Aircraft Engineering and Aerospace Technology: An International Journal, Vol. 79, No. 1, pp. 69-78.

- Kapoor, R., Adner, R. (2012), “What firms make vs. what they know: How firms' production and knowledge boundaries affect competitive advantage in the face of technological change”, Organization Science, Vol. 23 No. 5, pp.1227-1248.

- Knockaert, M., Ucbasaran, D., Wright, M., Clarysse, B. (2011), "The relationship between knowledge transfer, top management team composition, and performance: the case of science-based entrepreneurial firms”, Entrepreneurship Theory and Practice, Vol. 35 No. 2, pp. 777-803.

- Locke, K. (2001), Grounded Theory in Management Research, Sage, Thousand Oaks, CA.

- Love, P., Fong, P. S. W., Irani, Z. (2012) Management of knowledge in project environments, Elsevier: Oxford.

- Marshall, C. and Rossman, G. (1989), Designing Qualitative Research, Sage, London.

- Mills A., Smith T. (2011) "Knowledge management and organizational performance: a decomposed view", Journal of Knowledge Management, Vol. 15 No. 1, pp. 156-171.

- Pettersson, U. (2009) "Success and failure factors for KM: The utilization of knowledge in the Swedish Armed Forces", Journal of Universal Computer Science, vol. 15 No. 8, pp. 1735-1743.

- Pukkila, J. (2009) Critical success and failure factors of knowledge management implementation in a large multinational company, master thesis, Lappeenranta University of technology.

- Riege, A. (2005), “Three-dozen knowledge-sharing barriers managers must consider”, Journal of Knowledge Management, Vol. 9 No. 3, pp. 18-35.

- Rosenbusch, N., Brinckmann, J., Bausch, A. (2011) "Is innovation always beneficial? A meta-analysis of the relationship between innovation and performance in SMEs", Journal of Business Venturing, Vol. 26, pp. 441-457.

- Shaabani, E., Ahmadi, H., Yazdani, H. (2012) "Do interactions among elements of knowledge management lead to acquiring core competencies?”, Business Strategy Series, Vol. 13 No. 6, pp. 307-322.

- Singh, M.D. and Kant, R. (2007), "Knowledge Management as Competitive Edge for Indian Engineering Industries", in the proceedings of International Conference on Quality and Reliability (ICQR-2007), Chiang Mai, Thailand, 5-7 November, 2007, pp. 398-403. 
- Singh, M.D. and Kant, R. (2008), "Knowledge management barriers: An interpretive structural modeling approach”, International Journal of Management Science and Engineering Management, Vol. 3 No. 2, pp. 141-150.

- Snowden, D. (2000), "Liberating knowledge”, Joanna, R. (Ed.), Liberating Knowledge, Caspian Publishing: London, (pp. 6-19).

- Weber, R. O. (2007), “Addressing Failure Factors in Knowledge Management”, Electronic Journal of Knowledge Management, Vol. 5 No. 3, pp. 333-346.

- Zaied, A. N. H. (2012), “An integrated knowledge management capabilities framework for assessing organizational performance”, International Journal of Information Technology and Computer Science, Vol. 2, pp. 1-10. 